\title{
Lightning on transmission lines hazards and Prevention Measures
}

\author{
Wang Qinghao, Ge Changxin, Xue Zhicheng, Sun Fengwei, Wu Shaoyong, Li \\ Zhixuan, Shi Dongpeng, Ren Hao, Li Jinye, Ma Hui, Cao Feiyi \\ Fushun Power Supply Company, Liaoning Electric Power Company Limited, State Grid, China,
}

fushunpowersupply@163.com

Keywords: power transmission line, lightning hazard, prevention measures

\begin{abstract}
Through the analysis of lightning to the harmfulness of the power transmission line, puts forward the specific measures to prevent lightning accidents, improving insulation, installing controllable discharge lightning rod, reducing the tower grounding resistance, adding coupling ground wire and the proper use of send arrester electrical circuit transmission line. And take on the unit measures nearly were compared, statistics and analysis.
\end{abstract}

\section{Introduction}

Lightning accident is always an important factor affecting the reliability of the power supply of the electric line to send. Because of the randomness and complexity of lightning activity in the atmosphere, currently the world's research on knowledge transmission line lightning and many unknown elements. Lightning accident of overhead power transmission line is always a problem of safe power supply, lightning accidents accounted for almost all the accidents of $1 / 2$ or more line. Therefore, how to effectively prevent lightning, lightning damage reduced to more and more by transmission line of the relevant personnel to pay attention[1-2].

At present, the measures of lightning protection of transmission line itself mainly rely on the erection of the overhead ground wire of the tower top, its operation and maintenance work is mainly on the detection and reconstruction of tower grounding resistance. Due to its single lightning protection measures, can not well meet the requirements of lightning protection. And the installation of coupling ground wire, the implementation of the enhanced insulation level of transmission line lightning protection measures, subject to conditions, some of which can not be effectively implemented, such as the addition or replacement of insulators for large climbing distance method of synthetic insulator to improve line insulation, to prevent the lightning strikes the tower lightning voltage effect is good, but to prevent lightning the poor effects, and to increase the insulators by the tower head insulation gap and wire of safety distance constraints, so the line insulation enhancement is limited. And the installation of coupling ground wire is generally applicable to the hilly or mountainous crossing span, can go to the shielding effective protection function to the wire, with such striking distance principle is also reduced exposure arc wire. Effects of traffic transportation factors but the tower of strength, below the safety distance, crossing and line, thus erecting coupling ground wire for the old line is not easy to implement. So the research is not affected by the measures of lightning protection line conditions is very important, will be installing line arrester (needle), reducing tower ground resistance, a comprehensive analysis of the use of, to prevent lightning from their form of targeted starting, truly feasible and can receive the actual effect[3].

\section{The harm of lightning on transmission lines}

The main rack transmission lines for the grid (skeleton), its operation safety are the guarantee of the whole power grid safe operation. At present, the main performance of the transmission lines affected by lightning troubles of lightning trip-out, bolt, etc; More form of lightning tripping. So run of single power supply substation will total station blackout, directly affects the area of the whole power supply; At the same time, the higher the voltage grade, lines and lightning harm to the safe 
operation of the contradiction of the more prominent. Such as $500 \mathrm{kV}$ line, the line running at full capacity, when the lightning tripping, due to the line with transfer to instantaneous load, will cause multiple substation of $220 \mathrm{kV}$ and below power outages, the direct causes of the entire region's power outage, even can produce power grid collapse accidents due to other reasons, extend the influence of the lightning disturbance, causing a greater loss. Now, therefore, the design of the ultrahigh pressure line first line lightning protection design as a top priority [4, 5].

Transmission lines from lightning strike is mainly due to the condition of lightning strike to make transmission line insulator is punctured, the insulation of the line moment less, cause the wire connection to earth potential hardware, discharge of cross arm, or along the insulator flashover, residual until disconnection; Generally, lightning strike tend to occur on the $10 \mathrm{kV}$ line, $66 \mathrm{kV}$ and above line lightning strike rarely, almost none. The lightning protection of transmission lines, therefore, the emphasis should be on preventing lightning tripping accidents.

\section{Lightning trip out of transmission line}

The electric circuit of lightning strike accident mainly related to four factors: $50 \%$ of the line insulator discharge voltage; Presence of overhead ground wire; The intensity of lightning current. Tower's grounding resistance. Transmission lines all kinds of lightning protection measures has its pertinence, therefore, in the design of transmission lines, we choose way lightning protection from lightning trip must first clear transmission lines.

(1) Transmission lines around the strike cause analysis

According to transmission lines running experience, field measurement and simulation test have proved that lightning around the hit rate and ground wire to wire protection Angle, tower height and high voltage transmission lines through the terrain, landform and geological conditions. Mountains of transmission lines around the strike rate are about three times the ground transmission lines. Mountainous area design of transmission lines when inevitable there will be a large span, large span, the elevation difference is this line lightning resisting level of weak links; Some areas relatively strong lightning activity, make a section of the line than other line more vulnerable to lightning strike.

(2)Transmission lines back cause analysis

Lightning rod, the top or wire, lightning current flows through the tower body and earthing body, make the tower potential rise of the induced over-voltage on the phase conductors. If higher potential and phase conductors induced over-voltage synthesis tower potential difference over the high voltage transmission lines insulation flashover voltage value, namely the $\mathrm{Uj}_{\mathrm{j}}>\mathrm{U}_{50} \%$, flashover occurs between conductors and tower, the back flashover is flashover.

\section{High voltage transmission line lightning protection measures of power}

Clear causes send lightning trip out electric line, we can according to different area through the power transmission line of different geographical location, tower to take corresponding lightning protection measures. At present, mainly has the following several measures for lightning protection of transmission line:

(1) Strengthen the insulation level of transmission line

Insulation level and lightning withstand level is proportional to the power transmission line, to strengthen the detection of faulty insulators, ensure the transmission line with sufficient insulation strength is an important factor to improve the lightning withstand level of transmission line. As the commonly used to increase insulators or replacement for large climbing distance method of synthetic insulator to improve line insulation, to prevent the lightning strikes the tower lightning voltage effect is good, but to prevent the shielding effect is poor, and the increase of insulators by the tower head insulation gap and the guide line of safety distance constraints, so the line insulation of the enhancement is limited.

(2) Installing controllable discharge lightning rod

Controllable discharging lightning rod is the latest research achievement of State Grid Wuhan 
High Voltage Research Institute after long-term research on lightning protection and a lot of experiments and obtained high pressure. The needle to slow to change small current upward lightning discharge form release thundercloud charge, avoid downward ray strong flashover hazards as the design foundation. Through thousands of high-voltage discharge test proved that it is caused by upward lightning protection, has the advantages of high reliability, range, characteristics and is not affected by the height of protection. The correct principle, a new design idea, good protection performance, is a lightning protection device has a wide application foreground. In recent years, network in the country of $220 \mathrm{kV}$ in Fushun power supply company permanent line road (a total of 103 base tower) with controllable discharge lightning rod in 35 groups, from nearly 3 years of lightning accident level, there is a clear downward trend, 3 years occurred in 2 (the original lightning accidents per year on average, 5) lightning protection effect is very obvious, can generalize the work in the future. The discharge lightning rod is shown in Figure 1.

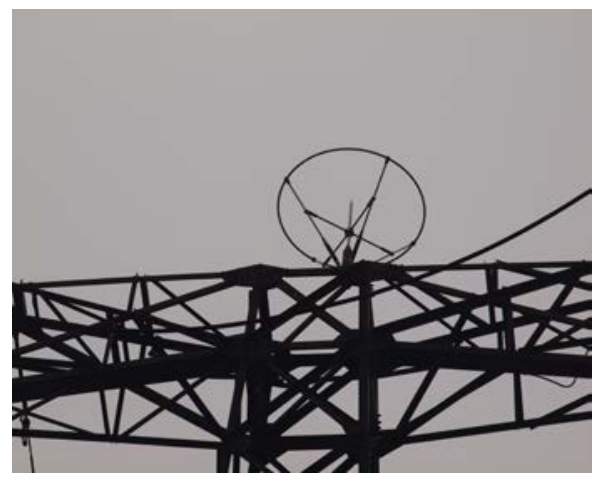

Figure 1 The controllable discharge lightning rod

(3)Reduce the tower grounding resistance

Transmission lines of grounding resistance is inversely proportional to the lightning resisting level, according to each of the soil resistivity tower, as far as possible to reduce the grounding resistance of tower, which is to improve the lightning resisting level of high voltage transmission lines, is the most economic and effective method. Must pay attention to reduce the grounding resistance to prevent around ray is invalid.

(4) Add ground coupling

Due to the coupling between the ground can make the wire and cable coupling coefficient increases, and through the thunder and lightning tower flow on both sides of the shunt, thus improve the lightning resisting level of the transmission lines. And coupling ground installation is generally applicable to the hills or mountains across, can lead to play an effective shielding protection, use and strike from the principle is also reduced exposure segment of the wire. But the strength of the tower, the safe distance, cross cross and lines at the bottom of the transportation, the influence of such factors as so erect coupling ground for the old line is not easy to implement

(5)The proper use of transmission line lightning arrester

Because lightning arrester installation tower and conductor is potential difference over the action of lightning arrester voltage, lightning arrester join shunt, ensure insulator flashover is not. According to actual operation experience, the lightning trip-out more frequently on the high voltage transmission lines of selective installed lightning arrester can achieve very good lightning protection effect. Across the country have already been used a certain number of transmission line lightning arrester, reflect the good operation. Figure 2 shows the transmission line lightning arrester. 


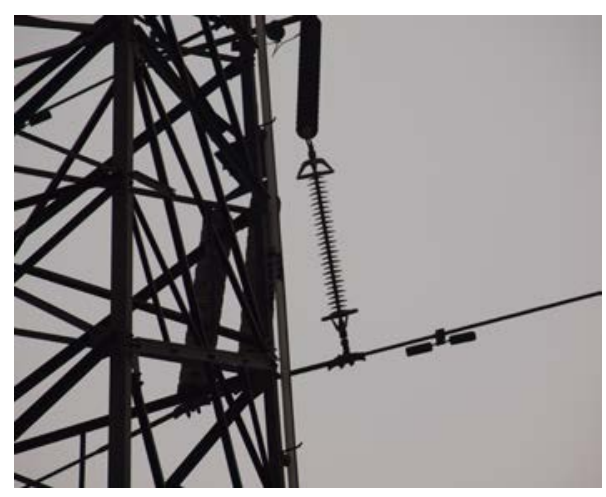

Figure 2 The transmission line lightning arrester

In 2010, 220kV Liu zhong(a total of 78 base tower), Liaogong line (a total of 85 base tower) were added but the line arrester (gapped) 21 group and 19 group, from nearly 4 years of lightning accident level, there is a clear downward trend, 4 years a total of 3 accidents happened in lightning (formerly an annual average of 5), the lightning protection effect is very significant.

\section{Conclusion}

To sum up, in order to prevent and reduce the pollution accident, the operation of transmission lines, we according to the transmission lines through regional lightning activity degree of strength characteristics, topography and soil resistivity of high and low, etc., in combination with transmission lines operating experience and system operation mode, etc., through comparing the necessary feasible improvement measures of lightning protection, improve the level of line lightning resisting, minimize the ray against accidents, lightning troubles will reduce losses to a minimum. At the same time we believe on transmission lines equipped with lightning arrester (needle), to reduce the grounding resistance is effective lightning protection measures.

\section{References}

[1] Xu Ying, XU Shi Heng. AC Power System Overvoltage Protection and Insulation. China Electric Power Press, 2006

[2] Qiu Zhixian. High Voltage Composite Insulators and Its Application. China Electric Power Press, 2006

[3] Tan Qiong, Li jingLu, Li Zhiqiang. Mountainous Grid Lightning Protection Technology. China Water Power Press, 2011

[4] Gao Jun. Grid to Prevent Pollution Flashover Technical Q\&A . China Electric Power Press, 2009

[5] Chen Huagang. Electrical equipment preventive test techniques for question answering. Hydraulic and electric power press, 1998 